\title{
Bridging the 'Valley of Death': Can Agile Principles Be Applied in Industry-Academia Research and Innovation Projects?
}

\author{
Irina-Emily Hansen ${ }^{1} \cdot$ Ola Jon Mork ${ }^{1} \cdot$ Torgeir Welo $^{2} \cdot$ Geir Ringen $^{2}$
}

Received: 27 April 2021 / Accepted: 16 September 2021 / Published online: 5 November 2021

(c) The Author(s) 2021

\begin{abstract}
Government funding supports industry-academia research and innovation projects in Norway, sharing the risk of the research component in innovation. However, funding alone may not be sufficient to overcome potential differences in collaborative agendas and ways of working. As a result, positive research outcomes often get stuck in the valley of death, instead of ending up as successful innovations that create value. To contribute to bridging the valley of death, we investigated the importance of six agile principles for collaborative industry-academia research and innovation projects, abbreviated IPN in Norway. The study was limited to the manufacturing sector. We surveyed 124 IPN project leaders (70 from industry; 54 from academia) to evaluate the importance of the knowledge management practices associated with the six agile principles across the three project stages. The statistical analyses indicate the consistency of the agile principles throughout the project stages. This means that agile principles are relevant for IPN projects and can be used as guidelines for improvement of the knowledge management practices. Moreover, the study identifies the agile principles that are perceived as most important to use in different stages of a project. It also identifies the different perceptions of the importance of agile principles of the project leaders from industry and academia. These findings can support project leaders who are implementing agile principles to industry-academia research and innovation projects. The results from the study can also support national and federal research/innovation councils in decision-making when assessing industrial research applications.
\end{abstract}

Keywords Agile principles · Knowledge management · Industry-academia · Research and innovation projects

\footnotetext{
This article belongs to the Topical Collection: Open Innovation Platforms Fostering Knowledge Ecosystems

Guest Editor: Anna Paola Codini, Tindara Abbate, Barbara Aquilani
}

Irina-Emily Hansen

irina-emily.hansen@ntnu.no

Extended author information available on the last page of the article 


\section{Introduction}

Governmental funding of collaboration between industry and academia in technology innovation is one of the ways to accelerate and scale up research and innovation (European Commission, n.d.). It allows industries to carry less investment risks, while providing access to a broader range of expertise and advanced technologies than they have in-house. For academia, such governmental funding schemes provide a great opportunity to develop new knowledge and stay updated on industrial needs, in addition to external funding, patents, and licensees emerging from such projects.

However, governmental incentives do not guarantee any success of collaborative industry-academia research and innovation projects. Fundamental differences in agendas, ways of working, and time perspectives create barriers for collaboration and decrease projects' innovation potential (Ankrah \& AL-Tabbaa, 2015; GalanMuros \& Davey, 2019; Perkmann et al., 2021). Even when industry and academia manage to collaborate effectively and achieve the results that are beneficial for industry, this is not always enough for successful technology realisation (Larsson et al., 2006; Perkmann et al., 2015). Lack of innovation outcomes is often linked to the so-called valley of death, which is a place where many of the results from industry-academia research and innovation projects end up (Maughan et al., 2013). Bridging the valley of death requires new approaches to traditional project management (Hansen et al., 2017; Jonsson et al., 2015; Laine et al., 2015).

Previously, a qualitative research study was conducted in order to gain understanding of the underlying reasons for innovation project challenges, and how to facilitate the projects to better achieve the research and innovation goals (Hansen et al., 2017; Hansen et al., 2018; Hansen et al., 2019a; Hansen et al., 2019c; Hansen et al., 2019b). The study proposes management practices that can increase the innovation potential from industry-academia research and innovation projects. It is proposed that implementation of practices should be done in three project stages, including planning, execution, and evaluation. These management practices seemed to be associated with the agile principles, which are the fundamentals of agile project management (APM) (Highsmith, 2009). APM has proven to be very effective for innovation projects within software development (Rigby et al., 2016b). Nevertheless, due to its inherent focus on responding rapidly to changing conditions, APM has also dispersed into other areas like manufacturing, sales, and marketing (Conforto et al., 2014; Cooper \& Sommer, 2016; Nelson, 2008; Rigby et al., 2016a; Rigby et al., 2018; Zhang \& Sharifi, 2007). Agile development has also spurred interest in the research community within collaborative industry-academia projects, and several studies refer to beneficial use of the agile principles. However, the studies largely concern software development, thus necessitating a call for studies on the agile principles' application in other areas of product development (Marchesi et al., 2007; Sandberg et al., 2011; Sandberg \& Crnkovic, 2017).

To contribute to this body of knowledge, this study explores project leaders' personal opinions about the importance of agile principles in industry-academia research and innovation projects in the manufacturing domain. 
The remainder of this paper is organised as follows: "Background" gives insight into the theory of APM and the knowledge gap concerning the application of agile principles to industry-academia research and innovation projects. "Research Objective, and Research Questions" introduces the research objective and the research questions. "Methodology" presents methodology and research design, including the data collection and analysis method. "Results" presents the findings related to the research questions, while "Discussion" discusses these results. "Conclusion" concludes the study.

\section{Background}

APM has proven to be effective for projects targeting innovation (Rigby et al., 2016a, 2016b). APM was inspired by the findings of Takeuchi and Nonaka published in the article 'The new new product development game' in 1986 (Takeuchi $\&$ Nonaka, 1986). The authors identified that the common reason for numerous successful innovations in Japanese companies was the new way of collaborating and organising product development. The inference was to 'stop running the relay race and take up rugby', implying that the traditional sequential project management approach cannot keep up with an instantly changing environment, and companies need to operate with self-organising, cross-functional teams that work with overlapping development phases. Later, in 2001, their findings together with other software development methodologies lay the foundation for the Agile Manifesto (Highsmith, 2009). These methodologies were different, but they had a common ground lessening and simplification of development rules for quicker adjustment to rapidly changing environments (Rigby et al., 2016b). The Agile Manifesto stated four basic agile values: individuals and interactions over processes and tools, working software over comprehensive documentation, customer collaboration over contract negotiation, and responding to change over following a plan. Twelve principles were developed to support the agile values. The principles fulfil the following criteria (Manifesto for Agile Software Development, n.d.):

-deliveries of the working product within shorter time cycles;

-tight collaboration between developers and businesspeople;

-empowering motivated individuals and self-organising project team;

-encouraging face-to-face interactions between all stakeholders;

-reducing comprehensive documentation and quality defects.

There exist some studies on agile applications in industry-academia research and innovation projects. In the studies within software development in Sweden, authors identified several best practices related to the agile principles that were applied in successful industry-academia research and innovation projects (Sandberg et al., 2011; Sandberg \& Crnkovic, 2017). The findings identified the importance of capability of projects to deal with fast-paced changing business environment. This implied that projects should address only the research questions that allow adjustment to changing industrial goals. Organising meetings for engineers and researchers 
as well as ensuring frequent deliverables to industry were also pointed out as determinants of innovation success related to the agile principles. The persistent practical deployment of the research results and the visible presence of researchers in industry were emphasised by other studies on agile in industry-academia software development (Grunbacher \& Rabiser, 2013; Wohlin et al., 2012). However, as the existing studies are in the software development domain, there is still a lack of evidence regarding application of agile principles in industry-academia innovation projects, for example, in manufacturing industries.

\section{Research Objective, and Research Questions}

The previous study on industry-academia collaboration in research and innovation projects in the manufacturing sector identified several significant findings. Figure 1 depicts the research framework beginning with a previous qualitative study, including a literature review, followed by a quantitative study (Hansen et al., 2017; Hansen et al., 2018; I. E. Hansen et al., 2019a; Hansen et al., 2019c; Hansen et al., 2019b). The literature analysis from the previous study (Step 1) revealed the critical factors that should be addressed in the projects. These include defining collaborative goals, facilitating knowledge creation processes, and accelerating the rate of learning.

Subsequently, the qualitative research (Step 2) aimed to get a deeper understanding of what can be done to address the aforementioned critical factors in practice. The study concentrated on innovation projects in the industrial sector (henceforth denoted as IPN projects), in Norway. This choice was made because the IPN project is a well-established form of industry-academia collaboration. However, even as approximately $50 \%$ of IPN projects reports innovation success, there is still a great room for improvement (Bergem et al., 2019).

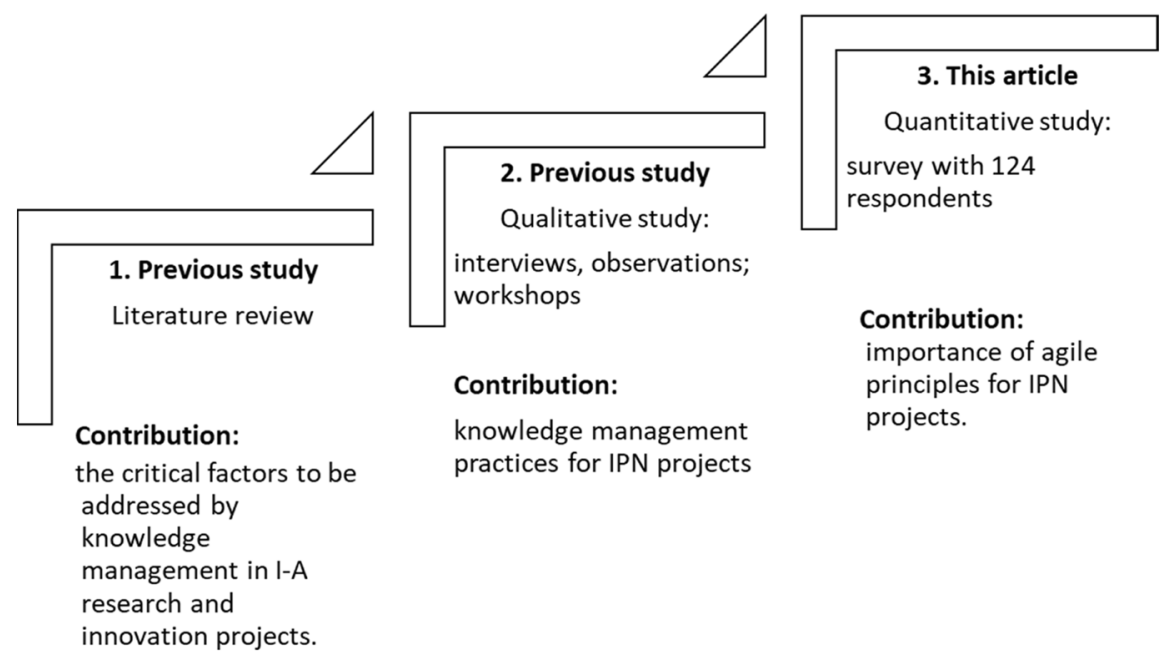

Fig. 1 Research process (I-A: industry-academia) 
IPNs are governmentally supported, research-based innovation projects between industry and academia, where the latter is typically a university or research institution. The project contract is between the Research Council of Norway (RCN) and the industrial company, while the academic institution is contracted to perform research within the project. The industrial company initiates the IPN and finances typically $60 \%$ of the total project costs through in-kind hours assigned to the project. RCN covers the costs related to the contracted research activities of the academic partner(s). An IPN project typically lasts 3 to 4 years and have an average total budget of 1.5 million EUR (The Research Council of Norway. Innovation projects in industrial sector, n.d.).

The data for the qualitative research was based on informal and formal semistructured interviews of selected project leaders and PhD students with experience in IPN projects. In addition, the first author of this paper had the opportunity to observe colleagues who worked on an IPN project almost daily over a 3-year period. This shows the researcher's prolonged engagement in the field being studied (Lincoln \& Guba, 1986). Several workshops with the researchers participating in different IPN projects were also used to complement the findings.

The qualitative study proposed a conceptual knowledge management (KM) model for industry-academia collaboration in research and innovation projects. The model integrates the organisational knowledge creation processes of Nonaka and Takeuchi in the context of IPN project with several modifications (Nonaka $\&$ Takeuchi, 1995). The first modification involves the specific management practices that support knowledge processes in the three stages of an IPN project, namely planning, execution, and evaluation. The second modification involves the use of new knowledge obtained during the project for continuous improvement of management practices.

Nevertheless, the core of the proposed conceptual KM model for industryacademia collaboration in research and innovation is the Nonaka and Takeuchi model, which has proven to be among the more robust models in the field of KM. However, it has its shortcomings. The model focuses on the practices that support knowledge creation and learning processes, but it does not address the principles that help to refine these practices (Dalkir, 2017). Meanwhile, a closer analysis of the results from the qualitative research on IPN projects showed that the identified management practices have a lot in common with six of the agile principles. In agile project management, the agile principles help project leaders to improve management practices and thereby optimise new product development continuously (Highsmith, 2009). Therefore, we decided to investigate if agile principles can do the same for IPN project leaders. Hence, the objective of this study is to investigate the potential of agile principles to support project leaders in the management of industry-academia research and innovation projects and to explore how the agile principles should be applied in different project stages.

The starting point for the study is to check whether the use of the agile principles is relevant for IPN projects. Thus, the first research question (RQ1) is: Are the agile principles aligned with the management practices throughout the IPN project?

If the consistency is confirmed, the next step is to investigate the use of agile principles in IPN projects. Therefore, the second research question (RQ2): How do 
project leaders perceive the importance of the agile principles in different stages of IPN projects?

Since academia and industry have different agendas for collaboration in research and innovation projects, it is likely that the differences may be reflected in their perceived importance of the agile principles. This leads to the third research question (RQ3): How do project leaders from industry and academia perceive the importance of agile principles in different stages of IPN projects?

\section{Methodology}

\section{Data Collection}

Table 1 presents the six agile principles from the Agile Manifesto (Manifesto for Agile Software Development, n.d.), which we found to be in line with the management practices identified in the previous study (Hansen et al., 2018; Hansen et al., 2019c; Hansen et al., 2019a; Hansen et al., 2019b). 'Flexibility' implies instant adaptation of the industry-academia innovation projects to the commonly changing industrial needs. 'Collaboration' and 'Communication' emphasise the need for close interaction between developers, researchers, and end-users for increasing knowledge creation and learning. 'Incremental and iterative learning' focuses on building knowledge together with stakeholders. 'Enabling environment' means that the management shall create conditions for the project team to work effectively and efficiently on innovation. This implies ensuring a self-organised, multi-disciplined project team, which has the authority needed to get the job done (Highsmith, 2009). 'Reflective actions' in the industry-academia context imply that the project team and the steering group will optimise the working methods based on changes and opportunities that arise during the course of the project.

Table 1 The principles from Agile Manifesto that are found to be relevant for IPN projects (Manifesto for Agile Software Development, n.d.)

\begin{tabular}{ll}
$\begin{array}{l}\text { Agile principles from the Agile Manifesto adapted to IPN } \\
\text { projects }\end{array}$ & $\begin{array}{l}\text { Shortening of the description of the } \\
\text { agile principles for the purpose of the } \\
\text { study }\end{array}$ \\
\hline $\begin{array}{l}\text { The project must handle changing requirements, even in late } \\
\text { development }\end{array}$ & Flexibility \\
$\begin{array}{l}\text { The company must collaborate closely with customers and } \\
\text { suppliers }\end{array}$ & Collaboration \\
$\begin{array}{l}\text { Face-to-face conversation is the best form for communication } \\
\begin{array}{l}\text { Early, continuous, and frequent delivery of valuable products } \\
\text { Management empowers self-organised multi-disciplinary } \\
\text { project teams }\end{array}\end{array}$ & $\begin{array}{l}\text { Communication } \\
\text { Encremental and iterative learning }\end{array}$ \\
$\begin{array}{l}\text { At regular intervals, the project team reflects on how to } \\
\text { become more effective and adjusts working methods } \\
\text { accordingly }\end{array}$ & Reflective actions \\
\hline
\end{tabular}


To answer the research questions, we developed a survey asking project leaders about their subjective opinions concerning the importance of agile management practices for innovation success of IPN projects. The survey included the management practices associated with the six agile principles across the three project stages, as shown in Tables 2, 3, and 4. In most cases, two important practices were defined for each agile principle in each project stage. In total, the survey included 38 practices.

The perceived importance of the defined practices was assessed on a five-point Likert scale, where ' 1 ' denotes 'not important' and '5' denotes 'very important'. Before sending the survey to the respondents, it was piloted with three project leaders from industry, university, and research institutions. They confirmed that a5-point Likert scale was suitable (Dawes, 2008; Joshi et al., 2015). Additional constructive feedback helped in improving the survey in several aspects. For instance, one of the

Table 2 The management practices related to the agile principles in the project planning stage

\begin{tabular}{|c|c|}
\hline Agile principles & Management practices \\
\hline Flexibility & $\begin{array}{l}\text { The project team continuously modifies innovation goals based on } \\
\text { the knowledge emerged during the project } \\
\text { The project planning team includes spin-offs as a possibility for } \\
\text { exploitation of the new knowledge }\end{array}$ \\
\hline Collaboration & $\begin{array}{l}\text { The university uses the innovation project with industry to build } \\
\text { knowledge in a long-term perspective } \\
\text { The industry uses the innovation project with universities to build } \\
\text { competence in a long-term perspective }\end{array}$ \\
\hline Communication & $\begin{array}{l}\text { Researchers from the university can apply and explain theoretical } \\
\text { knowledge in an industrial setting } \\
\text { The industry employees are open to adopting new knowledge created } \\
\text { in the innovation project }\end{array}$ \\
\hline Incremental and iterative learning & $\begin{array}{l}\text { The management of the industrial company assesses the value of the } \\
\text { project results when the project is completed } \\
\text { The management of the industrial company assesses the value of the } \\
\text { project results continuously during the project }\end{array}$ \\
\hline Enabling environment & $\begin{array}{l}\text { Innovation projects are crucial for the company's future } \\
\text { The management of university and industry provides full support and } \\
\text { independence to the project team } \\
\text { Both the industrial company and the university allocate the necessary } \\
\text { resources to the innovation project } \\
\text { The company's management approves the work packages and } \\
\text { objectives for the project } \\
\text { The company's management actively participates in the preparation } \\
\text { of the project's work packages and objectives }\end{array}$ \\
\hline Reflective actions & $\begin{array}{l}\text { The steering group reflects on how they can work effectively together } \\
\text { and adapts their working methods and attitudes accordingly } \\
\text { throughout the project } \\
\text { Both the industrial company and the university develop their } \\
\text { organisations in line with the opportunities that the innovation } \\
\text { project generates }\end{array}$ \\
\hline
\end{tabular}


Table 3 The management practices related to the agile principles in the project execution stage

\begin{tabular}{ll}
\hline Agile principles & Management practices \\
\hline Flexibility & The project team is working in a strategic direction \\
End users are involved in continuous testing of prototypes to find the \\
'real industrial needs' and to reject 'the constructed' needs \\
The technology integrator who is responsible for the implementation \\
of the research results in industry is involved in the project from an \\
early stage \\
Prototypes are built at the industrial company location, so that \\
everyone can contribute \\
Communication is done via face-to-face meetings and through \\
visualisation and prototype building \\
The core team in the project has a common interpretation for the \\
most important knowledge in the project \\
All departments in the organisation have the opportunity to provide \\
inputs and learn from the project along the way \\
The end user continuously helps to navigate the project's direction \\
The customer continuously helps to navigate the project's direction \\
The project team works independently and organises their own \\
progress \\
The project has a stable core team dedicated to the project \\
The project team reflects on how they can work effectively and \\
adapts their working methods and attitudes accordingly throughout \\
the project
\end{tabular}

comments was if the project leaders should base the answers on their general experiences with IPN projects or on a specific project. The pilot indicated that it was better for the respondents to refer to their general IPN project experience rather than that of one specific project, since it was considered beneficial for the study to utilise a broad range of project experience.

The respondents were project leaders for IPN projects, selected based on the following criteria:

- Company operates within the manufacturing industry;

- Project conducted during the time period 2011-2019.

We used Google forms (https://docs.google.com/forms) to create a survey. Before sending out the survey link, the respondents were contacted via a phone call to briefly explain the survey and its purpose. The intention was to motivate project leaders to participate in the study and thereby increase the response rate.

The survey was sent to 189 selected project leaders identified from the RCN database (The Research Council of Norway. Projectbank, n.d.) and to IPN project leaders that work in the engineering department at a university. The survey was not notified to the Data Protection Services, since the questionnaire did not contain information that could identify individuals directly or indirectly. Moreover, the questionnaire at any point of the process was not connected to identifying information 
Table 4 The management practices related to the agile principles in the project evaluation stage

\begin{tabular}{|c|c|}
\hline Agile principles & Management practices \\
\hline Flexibility & $\begin{array}{l}\text { The needs of industrial companies' customers are built into the } \\
\text { prototypes and demonstrators, and will, thus, form the basis for } \\
\text { learning during further development } \\
\text { Ongoing technology development is considered continuously } \\
\text { throughout the project }\end{array}$ \\
\hline Collaboration & $\begin{array}{l}\text { The end user is involved throughout the project to ensure that the } \\
\text { result integrates the practical knowledge needed to use the product } \\
\text { Stakeholders provide frequent feedback and their knowledge is } \\
\text { continuously built into the product }\end{array}$ \\
\hline Communication & $\begin{array}{l}\text { Demo and prototypes are used to create learning } \\
\text { Trust and mutual understanding are the basis for effective } \\
\text { communication between stakeholders }\end{array}$ \\
\hline Incremental and iterative learning & $\begin{array}{l}\text { Customers of the industrial company evaluate the results and make } \\
\text { new contributions to the innovation project at regular intervals } \\
\text { during the project period } \\
\text { Prototypes are built at the industrial company, so that everyone can } \\
\text { continuously provide input throughout the project period }\end{array}$ \\
\hline Enabling environment & $\begin{array}{l}\text { Those who are involved in the project have sufficient time for } \\
\text { learning, reflection, and knowledge building } \\
\text { Typical innovators in the industrial company, who are experts in the } \\
\text { application of knowledge, have a central role in the project group }\end{array}$ \\
\hline Reflective actions & $\begin{array}{l}\text { The project team continually reflects on how they learn and develop } \\
\text { new knowledge, consequently improving their methods throughout } \\
\text { the project }\end{array}$ \\
\hline
\end{tabular}

about each respondent such as their IP address or email address (Norwegian Centre for Research Data, n.d.). The reminder was sent once to all the respondents. Two weeks after sending out the survey, 124 responses were received.

\section{Data Analysis}

We used SPSS statistical software to analyse the data. To get a general overview of what the project leaders think of agile in IPN projects, we first examine the mean values and the related standard deviations (SD). As a rule of thumb, a SD that is closer to one indicates that values are spread out over a wider range (Ringdal, 2018).

For RQ1, we apply a confirmatory factor analysis (FA) that identifies factor loadings. A factor loading exceeding 0.4 would indicate adequate correlation between the management practices and the corresponding agile principles (Pallant, 2020).

Next, we evaluate Cronbach's alpha (CA) that indicates the consistency of the entire survey and, thus, evaluates its reliability. CA values above 0.6 are considered acceptable. The higher the CA, the higher the internal consistency (Pallant, 2020).

To test the validity of the correlations between the practices and the agile principles, we evaluate average variance extracted (AVE). An AVE $>0.50$ indicates that more than half of the indicator variance is contained within the construct score (Hair 
et al., 2018). However, following the recommendations of Fornell and Larker, if the AVE is close to 0.4 and the reliability (CA) is higher than 0.6 , the validity of the correlations is still adequate and can be accepted (Fornell \& Larcker, 1981).

Furthermore, we investigate the existence of discriminant validity to examine consistency between the project stages. Discriminant validity is confirmed if the square root of AVE is higher than the latent variable's correlation with other constructs.

The factor loadings, CA, AVE, and existence of discriminant validity indicate that the management practices correspond well to the agile principles in the three project stages. This indicates an affirmative response for RQ1, justifying the use of the survey to answer the other research questions.

For RQ2, we apply factor analysis to identify correlation coefficients between the agile principles in three project stages. Correlation coefficients above 0.5 are considered to indicate high correlation. Correlation coefficients between 0.3 and 0.49 denote that the variables that are moderately correlated. Correlation coefficients that are less than 0.3 have little, if any, (linear) correlation (Pallant, 2020).

Next, we apply a one-way analysis of variance (t-test) to answer RQ3. The $t$-test identifies if there is a significant difference in assessing the importance of the agile principles between the project leaders from industry and academia. A $p$-value lower than or equal to 0.05 indicates statistically significant differences between the two groups (Pallant, 2020).

\section{Results}

Table 5 presents the descriptive statistics, in terms of means and standard deviations, of the responses of 124 project leaders regarding the perceived importance of the application of agile principles for the success of IPN projects.

In the project planning stage, the highest average value is predicted for the agile principle 'Communication', closely followed by 'Collaboration'. The agile principle 'Reflective actions' has the lowest mean value. In the project execution stage,

Table 5 Descriptive statistics of the responses of 124 project leaders regarding their perception of the importance of agile principles in the context of each project stage

\begin{tabular}{|c|c|c|c|c|c|c|}
\hline \multirow[b]{2}{*}{ Agile principles } & \multicolumn{2}{|c|}{$\begin{array}{l}\text { Project planning } \\
\text { stage }\end{array}$} & \multicolumn{2}{|c|}{$\begin{array}{l}\text { Project execution } \\
\text { stage }\end{array}$} & \multicolumn{2}{|c|}{$\begin{array}{l}\text { Project } \\
\text { evaluation stage }\end{array}$} \\
\hline & Mean & SD & Mean & SD & Mean & SD \\
\hline Flexibility & 3.89 & 0.77 & 4.13 & 0.59 & 4.04 & 0.60 \\
\hline Collaboration & 4.23 & 0.73 & 3.68 & 0.85 & 3.83 & 0.74 \\
\hline Communication & 4.33 & 0.58 & 3.95 & 0.61 & 4.32 & 0.57 \\
\hline Incremental and iterative learning & 4.12 & 0.60 & 3.55 & 0.61 & 3.53 & 0.74 \\
\hline Enabling environment & 3.93 & 0.55 & 4.20 & 0.63 & 3.97 & 0.63 \\
\hline Reflective actions & 3.77 & 0.72 & 3.94 & 0.81 & 3.69 & 0.88 \\
\hline
\end{tabular}

$S D$ standard deviation 
the agile principle 'Enabling environment' exhibits the highest mean value, whereas 'Incremental and iterative learning' has the lowest. In the project evaluation stage, the respondents gave the highest score to 'Communication' and the lowest to 'Incremental and iterative learning'.

However, it should be noted that the statistics demonstrate higher standard deviations for some principles, which indicates a wider range of perceptions for these principles (Ringdal, 2018). Notably, the agile principles 'Reflective actions' and 'Collaboration' have the highest standard deviation across all project stages.

\section{Results Underpinning the Answer to RQ1}

Table 6 presents the results of the factor analysis, which reveals that in the project execution stage, the agile principle, 'Communication', reports low loading (0.368). The loadings for the rest of the agile principles exceed 0.442 , indicating sufficient correlation between the management practices and the agile principles within each of the project stages.

Table 6 also reports the results of reliability test, indicating that CA exceeds 0.6 in all project stages, thereby confirming the reliability of the survey.

Furthermore, Table 6 shows the validity of the study. Calculation of AVE for all stages reveals two numbers slightly lower than 0.4 . However, it is believed that

Table 6 Factor loadings, CA, and AVE of the survey responses

\begin{tabular}{|c|c|c|c|c|}
\hline Project stages (construct) & $\mathbf{C A}$ & AVE & Agile principles (indicators) & Loadings \\
\hline \multirow[t]{6}{*}{ Project planning } & \multirow[t]{6}{*}{0.642} & \multirow[t]{6}{*}{0.382} & Flexibility & 0.713 \\
\hline & & & Collaboration & 0.643 \\
\hline & & & Communication & 0.622 \\
\hline & & & Incremental and iterative learning & 0.724 \\
\hline & & & Enabling environment & 0.442 \\
\hline & & & Reflective actions & 0.512 \\
\hline \multirow[t]{6}{*}{ Project execution } & \multirow[t]{6}{*}{0.66} & \multirow[t]{6}{*}{0.408} & Flexibility & 0.462 \\
\hline & & & Collaboration & 0.787 \\
\hline & & & Communication & 0.368 \\
\hline & & & Incremental and iterative learning & 0.615 \\
\hline & & & Enabling environment & 0.646 \\
\hline & & & Reflective actions & 0.643 \\
\hline \multirow[t]{6}{*}{ Project evaluation } & \multirow[t]{6}{*}{0.782} & \multirow[t]{6}{*}{0.359} & Flexibility & 0.643 \\
\hline & & & Collaboration & 0.524 \\
\hline & & & Communication & 0.553 \\
\hline & & & Incremental and iterative learning & 0.645 \\
\hline & & & Enabling environment & 0.568 \\
\hline & & & Reflective actions & 0.649 \\
\hline
\end{tabular}

$C A$ Cronbach's alpha, $A V E$ average variance extracted 
Table 7 Discriminant validity coefficients

\begin{tabular}{llll}
\hline & Project planning & Project execution & Project evaluation \\
\hline Project Planning & 0.618 & & \\
Project Execution & 0.485 & 0.639 & \\
Project Evaluation & 0.457 & 0.57 & 0.599 \\
\hline
\end{tabular}

the validity of the survey is still adequate since CA is higher than 0.6 (Fornell \& Larcker, 1981).

Discriminant validity coefficients, using the square root of AVE, are presented in Table 7. The square root of AVE is higher than the latent variable's correlation with other project stages, which indicates validity of the connections between the management practices and the corresponding agile principles in the respective project stages.

Overall, therefore, the results show that the management practices are aligned with the agile principles across the three stages of IPN projects.

\section{Results Underpinning the Answer to RQ2}

The SPSS row data underpinning the answer to RQ2 is presented in Table 11 in the Appendix. The results have been structured and presented in Figs. 2 and 3.

Figure 2 depicts the agile principles that have strong and medium interconnections between the different project stages.

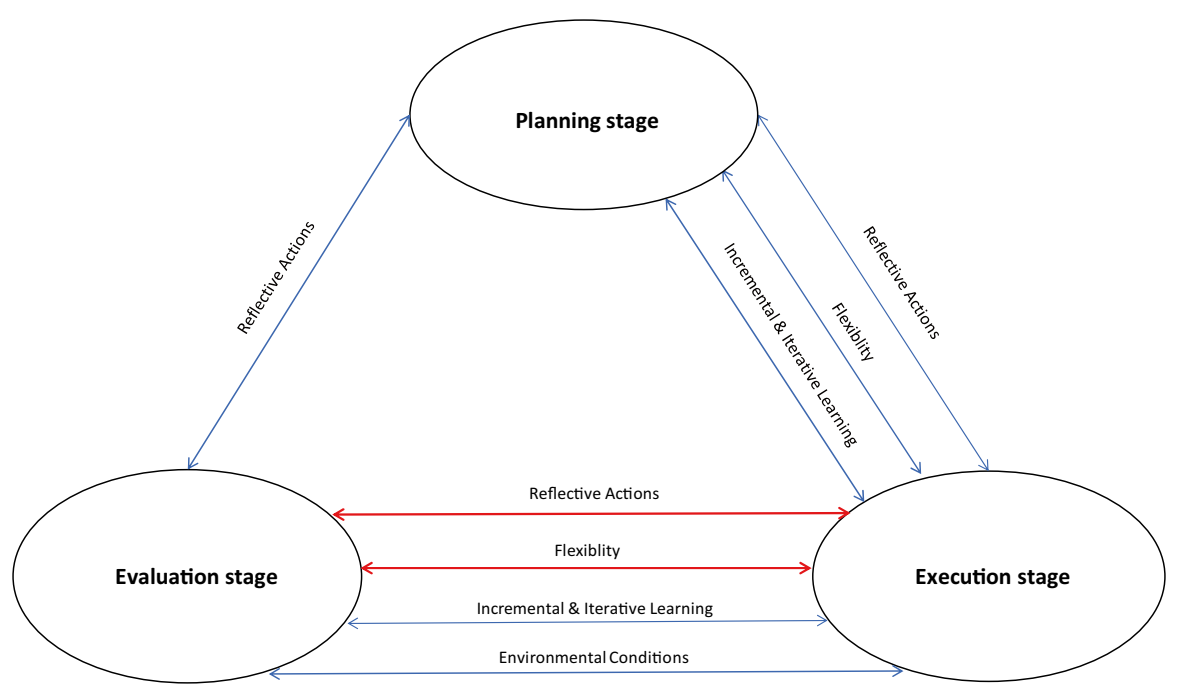

Fig. 2 Agile principles showing strong and medium interconnections between different project stages of IPN project 
Planning stage
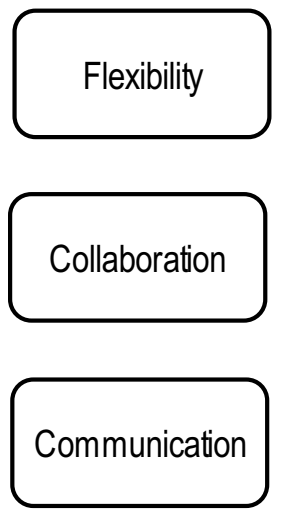

Incremental \& therative Learning

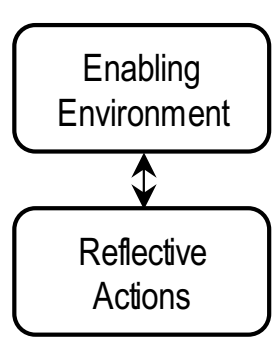

\section{Evaluation stage}
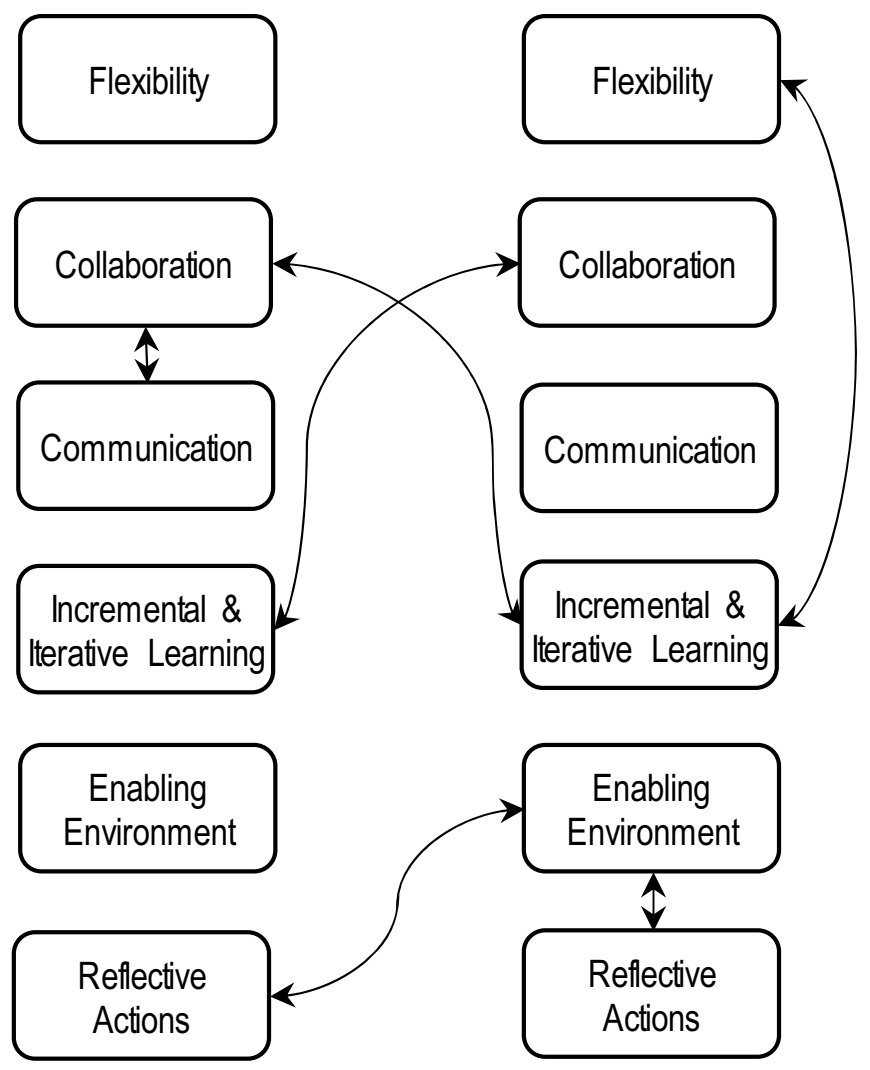

Fig. 3 Cross-correlations for the agile principles in the three stages of IPN projects

The execution and evaluation stages have strong correlations with each other through the agile principles 'Flexibility' and 'Reflective actions', and moderate correlations through the principles 'Incremental and iterative learning' and 'Enabling environment'. The planning and execution stages have moderate correlations with each other through the agile principles 'Flexibility', 'Incremental and iterative learning', and 'Reflective actions'. The evaluation and planning stages demonstrate moderate correlation with each other through the agile principle 'Reflective actions'. Thus, 'Reflective actions' is the only principle that reports correlations throughout all the three stages.

Additionally, factor analysis shows that 'Reflective actions' in the execution stage has the strongest correlations with all the other principles in all stages (Table 11).

'Reflective actions' stands out in the cross-correlations analysis of the principles as well, which is shown in Fig. 3. Strong connections were found between this principle and 'Enabling environment' in the planning stage as well as between the execution and evaluation stages. 
The lowest correlations among all the stages were identified for 'Collaboration'. However, in terms of cross-correlations, 'Collaboration' is strongly interrelated with 'Communication' in the execution stage. Interestingly, cross-correlations between 'Collaboration' and 'Incremental and iterative learning' were observed between the execution and the evaluation stages. The agile principle 'Incremental and iterative learning' also has a strong interrelationship with 'Flexibility' in the evaluation stage.

\section{Results Underpinning the Answer to RQ3}

In the next analysis, the respondents were divided into two categories - industry and academia. The former (70 respondents) included leaders of IPN projects who are employed in the industry domain. The 'academia' category (54 respondents) were leaders of IPN projects who were employees in a research institution or university.

The results for the planning stage are shown in Table 8 and reveal very little significant differences between how project leaders with industrial and academic backgrounds rate the importance of the agile principles. The only statistically significant difference between the two groups is observed for the principle 'Enabling environment', with a $p$ value of 0.009 .

Table 9 shows the differences between the two groups in the execution stage. The most significant difference is identified for 'Collaboration' with a $p$ value of 0.007 . The industry group gives this principle higher importance than academia. 'Flexibility' is the other agile principle that shows statistically significant differences between the two groups with a $p$ value of 0.04 . Both groups assess this principle relatively high on an absolute scale -4.22 and 4.00 for industry and academia, respectively.

Only one agile principle was found to be perceived differently between the two groups in the project evaluation stage. As given in Table 10, the most significant differences were identified for 'Enabling environment', with a $p$ value of 0.001 . The relative importance of this principle is rated higher by the industry respondents than by those in academia.

Table 8 T-test: differences between groups of leaders in the project planning stage

\begin{tabular}{|c|c|c|c|c|c|}
\hline Source & $N$ & Mean & Comparing groups & Mean difference & $p$ value \\
\hline \multirow[t]{2}{*}{ Flexibility } & 70 & 3.97 & Industry & 0.19 & 0.183 \\
\hline & 54 & 3.78 & Academia & & \\
\hline \multirow[t]{2}{*}{ Collaboration } & 70 & 4.27 & Industry & 0.1 & 0.466 \\
\hline & 54 & 4.18 & Academia & & \\
\hline \multirow[t]{2}{*}{ Communication } & 70 & 4.26 & Industry & -0.19 & 0.072 \\
\hline & 54 & 4.45 & Academia & & \\
\hline \multirow[t]{2}{*}{ Incremental and iterative learning } & 70 & 4.17 & Industry & 0.14 & 0.234 \\
\hline & 54 & 4.04 & Academia & & \\
\hline \multirow[t]{2}{*}{ Enabling environment } & 70 & 4.03 & Industry & 0.27 & 0.009 \\
\hline & 54 & 3.77 & Academia & & \\
\hline \multirow[t]{2}{*}{ Reflective actions } & 70 & 3.79 & Industry & 0.04 & 0.724 \\
\hline & 54 & 3.75 & Academia & & \\
\hline
\end{tabular}

$p$ value $\leq 0.05=$ significant difference 
Table $9 T$-test: difference between groups of leaders in the project execution stage

\begin{tabular}{|c|c|c|c|c|c|}
\hline Source & $N$ & Mean & Comparing groups & Mean difference & $p$ value \\
\hline \multirow[t]{2}{*}{ Flexibility } & 70 & 4.22 & Industry & 0.22 & 0.04 \\
\hline & 54 & 4.00 & Academia & & \\
\hline \multirow[t]{2}{*}{ Collaboration } & 70 & 3.85 & Industry & 0.42 & $\mathbf{0 . 0 0 7}$ \\
\hline & 54 & 3.44 & Academia & & \\
\hline \multirow[t]{2}{*}{ Communication } & 70 & 3.95 & Industry & -0.02 & 0.88 \\
\hline & 54 & 3.97 & Academia & & \\
\hline \multirow[t]{2}{*}{ Incremental and iterative learning } & 70 & 3.61 & Industry & 0.15 & 0.2 \\
\hline & 54 & 3.46 & Academia & & \\
\hline \multirow[t]{2}{*}{ Enabling environment } & 70 & 4.24 & Industry & 0.08 & 0.478 \\
\hline & 54 & 4.16 & Academia & & \\
\hline \multirow[t]{2}{*}{ Reflective actions } & 70 & 3.97 & Industry & 0.07 & 0.624 \\
\hline & 54 & 3.90 & Academia & & \\
\hline
\end{tabular}

\section{Discussion}

\section{RQ1: Are the Agile Principles Aligned with the Management Practices Throughout the IPN Project?}

The factor analysis, aimed at answering RQ1, identified adequate values of factor loadings for all agile principles, except the principle of 'Communication' in the execution stage. The results of CA, AVE, and discriminant validity coefficients showed significant correspondence between all agile principles and the related management practices across the three project stages. This may compensate for the slightly low factor loading for the principle 'Communication'.

Table $10 T$-test: difference between groups of leaders in the project evaluation stage

\begin{tabular}{lllllc}
\hline Source & $\boldsymbol{N}$ & Mean & Comparing groups & Mean difference & $\boldsymbol{p}$ value \\
\hline Flexibility & 70 & 4.10 & Industry & 0.15 & 0.178 \\
Collaboration & 54 & 3.95 & Academia & & 0.054 \\
Communication & 70 & 3.93 & Industry & 0.26 & 0.126 \\
& 54 & 3.68 & Academia & & 0.16 \\
Incremental and iterative learning & 70 & 4.39 & Industry & & 0.45 \\
& 54 & 4.23 & Academia & 0.1 & $\mathbf{0 . 0 0 1}$ \\
Enabling environment & 54 & 3.47 & Academia & & \\
& 70 & $\mathbf{4 . 1 2}$ & Industry & 0.39 & \\
Reflective actions & 54 & $\mathbf{3 . 7 4}$ & Academia & \multirow{2}{*}{0.052} \\
& 70 & 3.82 & Industry & & \\
\hline
\end{tabular}


However, it is important to understand project leaders' perception of the 'Communication' principle. This is of particular interest since proper communication is important in collaborative knowledge creation (Krogh et al., 2000; Nonaka et al., 2006).

Innovation combines knowledge embodied in different fields of expertise, and it is well documented that different organisations, and even different departments within an organisation, have challenges with communication. At the individual level, experts from different knowledge fields frequently have challenges to interact and understand each other (Amabile et al., 2005; Fleming et al., 2007; GalanMuros \& Davey, 2019; Milliken et al., 2003). As a countermeasure, APM focuses on daily face-to-face interactions of businesspeople and developers throughout the project (Highsmith, 2009; Manifesto for Agile Software Development, n.d.).

However, an IPN project does not involve such frequent communication. An IPN project is typically 'plan driven' and works towards intermediate and longterm project goals. IPN projects rely on structured project plans with formal objectives, activities, and milestones throughout the project period. Since the project team has scheduled meetings (say every 14th day), communication in the project tends to be more in the form of written reports, and lesser via face-toface discussions. This might explain why project leaders with experience in structured IPN projects perceive the importance of the 'Communication' principle to be lower than other principles. However, according to KM fundamentals, organisational learning relies on individual knowledge (Chesbrough \& Bogers, 2014; Nonaka et al., 2006). Therefore, industry and academia should direct their attention to the application of the 'Communication' principle.

Overall, the results related to RQ1 support the alignment of the agile principles and the management practices in IPN projects. The alignment is also confirmed in all three project stages. Thereby, the results on RQ1 verify the scientific rigor of the survey as a research instrument for collecting data, which, in turn ensures that the results for the research questions are valid and reliable. Next, the identified consistency of the agile principles means that management practices in the survey accurately reflect the corresponding agile principles in three project stages; i.e., the project leaders can trust the categorisation of the management practices in relation to the agile principles in IPN projects. Thus, project leaders can adapt the agile principles as guidelines for improving management practices.

\section{RQ2: How Do Project Leaders Perceive the Importance of the Agile Principles in Different Stages of IPN Projects?}

The findings related to RQ2 show which of the agile principles are perceived as consistent throughout the project stages. The results show that 'Incremental and iterative learning', 'Flexibility', and 'Reflective actions' are perceived as most important for IPN projects. The correlations between the agile principles show that if one of these principles is used in the execution stage, it will be also used in the planning and in the evaluation stages. However, only the use of 'Reflective actions' in the evaluation stage triggers its use in the planning stage. 
We will now elaborate on the results in terms of each of these three principles.

Application of the 'Incremental and iterative learning' principle will support IPN projects by the integration of each stakeholder's unique knowledge domain (Kazadi et al., 2016; Laine et al., 2015). Addressing stakeholders' knowledge in the execution stage will trigger examinations in the evaluation stage and adaptions in the planning stage. This feedback loop will help the project team to navigate the project (Schulze et al., 2014). However, the project leaders will not use 'Incremental and iterative learning' between the evaluation and the planning stages. This means that stakeholders' innovative strategy will not benefit from the IPN project since organisational knowledge creation requires transformation of knowledge learned at the project-team level to the organisational level (Nonaka et al., 2000; Nonaka et al., 2006). If the stakeholders do not expand their knowledge base through collaboration, they cannot contribute to IPN projects to the full extent (Cohen \& Levinthal, 1990; Zahra \& George, 2002).

The 'Flexibility' principle is about exploring, failing, and continuously developing new products or processes to ensure continuous adaptability to changing requirements (Conforto et al., 2014; Yannou, 2013). The results demonstrate how adaptation to the changes made in the execution stage will be assessed in the evaluation stage and will consequently trigger a response in the planning stage. This feedback loop shows that the IPN project will adapt to the changes at the project-team level. However, project leaders will not use the 'Flexibility' principle between the evaluation and the planning stages. This indicates that the continuous changes in customers' needs and technology development will not be taken into consideration by the project (Sandberg \& Crnkovic, 2017). The detachment from the organisational strategies will also not allow for reallocation of the resources based on shifting needs of the IPN project (Lazonick, 2006; West et al., 2014).

'Reflective actions' is the only principle that has strong and moderate correlations between all project stages. The principle is also significantly correlated to all the other principles within the execution stage, indicating the importance of enabling team dialogues, workshops, seminars, as well as informal and formal team platforms to discuss results, experiments, and models. The correlations of the 'Reflective actions' principle demonstrate that project leaders emphasise the importance of inspections and adaptation of the working methods at the level of the project team and the organisation (Derby et al., 2006; Nonaka et al., 2000).

Regarding cross-principle correlations, there are strong correlations between the 'Reflective actions' and 'Enabling environment' principles within the planning and evaluation stages, as well as between the execution and evaluation stages. These correlations emphasise that the management should provide all necessary resources for the project team to work effectively and efficiently. The management should reflect on the changes that occur during the project and make necessary adjustments in the resources needed to run the project. From the knowledge perspective, time is one of the vital resources. Giving the project team enough time to work on a project is a precondition for people's will to invest time in building knowledge with others (Krogh et al., 2000; Lazonick, 2006; Reagans \& McEvily, 2003). 
The evidence from previous studies show that the projects in which the project team have insufficient time produce lower innovation as compared to the projects where the team gets necessary support from management (Pertuzé et al., 2010).

\section{RQ 3: How Do Project Leaders from Industry and Academia Perceive the Importance of the Agile Principles in Different Stages of IPN Projects?}

The findings related to RQ3 identify the agile principles that are perceived to be more important by the industry than by academia.

In the planning and evaluation stages, it is the 'Enabling environment' principle. The IPN project and academic career require the academics to make the research public. Therefore, academics dedicate considerable time to work on publications rather than to ensure implementation of research results. Meanwhile, the industry's concern is to facilitate project team work to make the IPN project successful.

'Flexibility' in the execution stage is the other principle that is perceived to be more important by the industry than by academia. Industry is the owner of the project and must deal with any challenges that arise during development process. Thus, integrating flexibility into the IPN project is a major concern for industry (Durney \& Donnelly, 2015; Marchesi et al., 2007).

'Collaboration' in the execution stage is another principle that is perceived as being more important by the industry than by academia. Industry is in charge of organising and facilitating the collaboration between the stakeholders on one side and the project team on the other (Kazadi et al., 2016; Rigby et al., 2016a). The principle supports development of their own language and norms, thereby fostering a 'community of innovation' with its inherent socialisation context (Foss et al., 2011; Nonaka et al., 2000). The context provides for trust and mutual understanding that are vital for collaborative knowledge creation and learning processes (Jacob et al., 2000; Laine et al., 2015). In this manner, the principle 'Reflective actions' helps industry and academia to build similar knowledge bases and knowledge assimilation processes. The similarity is necessary to leverage knowledge learned from collaborative projects and to build long-term partnerships in research and innovation (Carayannis et al., 2000; Cohen \& Levinthal, 1990).

\section{Conclusion}

The objective for this study was to investigate the potential of the agile principles in supporting project leaders in management of industry-academia research and innovation projects. In the presence of such potential, we explored how the agile principles should be applied in different project stages.

To achieve the research objectives, we surveyed 124 IPN project leaders (70 from industry; 54 from academia) in Norway, to evaluate the importance of the management practices associated with the six agile principles across the three stages of IPN projects. 
Regarding RQ1, the statistical analyses indicate the alignment of the agile principles and the management practices throughout the project stages. Thereby, the results verify the scientific rigor of the survey as a research instrument for collecting data, which, in turn ensures that the results for the research questions are valid and reliable (Pallant, 2020). Next, the identified consistency of the agile principles throughout the three project stages means that management practices in the survey accurately reflect the corresponding agile principles in three project stages. This means that agile principles are relevant for IPN projects and can be used as guidelines for improving knowledge management practices.

With respect to RQ2, the study identifies the agile principles 'Reflective actions', 'Incremental and iterative learning', and 'Flexibility' as perceived to be the most important in IPN project. These findings can support project leaders implementing the agile principles to industry-academia research and innovation projects.

Nevertheless, the identified importance of the agile principles also highlights the critical aspects related to knowledge management in IPN projects. The study shows that 'Reflective actions' is the only principle that supports knowledge creation and learning processes throughout the three project stages. The finding emphasises the importance of improving the collaborative working methods both on the project level and strategic organisational levels. Meanwhile, 'Incremental and iterative learning' and 'Flexibility' principles are perceived to be important to follow on the project-team level, but not on the strategic level. From the organizational knowledge creation perspective, following 'Incremental and iterative learning' would entail transformation of new knowledge learned on the project level to the strategic level (Nonaka et al., 2006). In this way, industry, academia, and other stakeholders would be able to integrate new knowledge from the IPN project in their innovation strategies. The absence of such potential means lost opportunity for partners to increase innovative capability and contribute to the growth of a knowledge-based society (Carayannis \& Campbell, 2020; Lundvall, 2012). Additionally, not following the 'Flexibility' principle on the strategic level implies that the continuous changes in customers' needs and technology development will not be taken into consideration by the project. This can lead to the situation when there will be no need for innovation that was required before changes. Consequently, the innovation will fail (Rigby et al., 2016a).

The results for RQ3 revealed some differences in how project leaders from industry and academia perceive the importance of the agile principles in different stages of IPN projects. Unlike the academics, the industry perceives several agile principles to be more important, particularly 'Enabling environment' in the planning and evaluation stages, and 'Flexibility' and 'Collaboration' in the execution stage.

Awareness of these different perceptions of the importance of different agile principles should be taken into consideration when implementing agile principles in IPN projects.

The results from the study can also support national and federal research/innovation councils in decision-making when assessing industrial research applications.

Overall, the study indicates the potential of applying agile principles for improving management practices in industry-academia research and innovation projects. 
This implies that agile principles can potentially become a management tool for supporting industrialisation of research results, thereby bridging the valley of death in such projects. Therefore, this study calls for further research on purposeful application of agile principles for refining management practices in industry-academia research and innovation projects.

\section{Appendix}

Table 11 Factor analysis: correlation between agile principles in different project stages

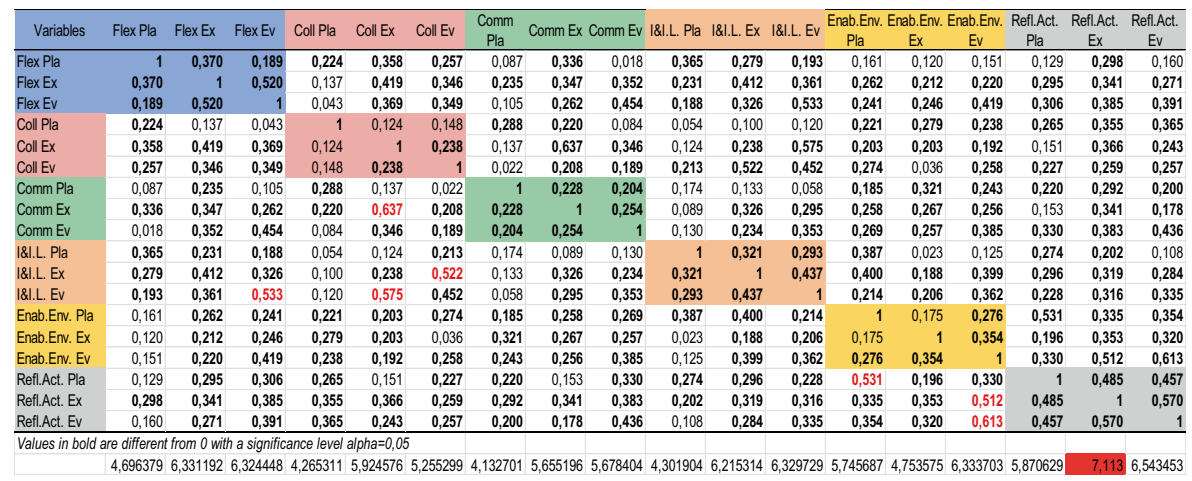

Funding Open access funding provided by NTNU Norwegian University of Science and Technology (incl St. Olavs Hospital - Trondheim University Hospital).

Open Access This article is licensed under a Creative Commons Attribution 4.0 International License, which permits use, sharing, adaptation, distribution and reproduction in any medium or format, as long as you give appropriate credit to the original author(s) and the source, provide a link to the Creative Commons licence, and indicate if changes were made. The images or other third party material in this article are included in the article's Creative Commons licence, unless indicated otherwise in a credit line to the material. If material is not included in the article's Creative Commons licence and your intended use is not permitted by statutory regulation or exceeds the permitted use, you will need to obtain permission directly from the copyright holder. To view a copy of this licence, visit http://creativecommons.org/ licenses/by/4.0/.

\section{References}

Amabile, T. M., Barsade, S. G., Mueller, J. S., \& Staw, B. M. (2005). Affect and creativity at work. Administrative Science Quarterly, 50(3), 367-403. https://doi.org/10.2189/asqu.2005.50.3.367

Ankrah, S., \& AL-Tabbaa, O. (2015). Universities-industry collaboration: A systematic review. Scandinavian Journal of Management, 31(3), 387-408. https://doi.org/10.1016/j.scaman.2015.02.003.

Bergem B.G., Bremnes. H., \& Sandsmark M. (2019). Resultatmaling av brukerstyrt forskning 2017. https:// www.moreforsk.no/publikasjoner/rapporter/samfunn/resultatmaling-av-brukerstyrt-forskning-2017/ $1075 / 3343 /$ 
Carayannis, E. G., Alexander, J., \& Ioannidis, A. (2000). Leveraging knowledge, learning, and innovation in forming strategic government-university-industry (GUI) R\&D partnerships in the US, Germany, and France. Technovation, 20(9), 477-488

Carayannis, E. G., \& Campbell, D. F. J. (2020). Mode 3 knowledge production in quadruple helix innovation systems: Quintuple helix and social ecology. In E. G. Carayannis (Ed.), Encyclopedia of Creativity, Invention, Innovation and Entrepreneurship (pp. 1668-1676). Springer International Publishing. https://doi.org/10.1007/978-3-319-15347-6_310

Chesbrough, H., \& Bogers, M. (2014). Explicating open innovation. In New frontiers in open innovation (pp. 3-28). Oxford University Press. https://doi.org/10.1093/acprof:oso/9780199682461.003.0001

Cohen, W. M., \& Levinthal, D. A. (1990). Absorptive capacity: A new perspective on learning and innovation. Administrative Science Quarterly, 35(1), 128. https://doi.org/10.2307/2393553

Conforto, E. C., Salum, F., Amaral, D. C., da Silva, S. L., \& de Almeida, L. F. M. (2014). Can agile project management be adopted by industries other than software development? Project Management Journal, 45(3), 21-34. https://doi.org/10.1002/pmj.21410

Cooper, R. G., \& Sommer, A. F. (2016). The agile-stage-gate hybrid model: A promising new approach and a new research opportunity. Journal of Product Innovation Management, 33(5), 513-526. https://doi.org/10.1111/jpim.12314

Dalkir, K. (2017). Knowledge Management in Theory and Practice, Third Edition. Cambridge: MIT Press. https://mitpress.mit.edu/books/knowledge-management-theory-and-practice-third-edition

Data Protection Services. In Norwegian Center for Research Data: https:/www.nsd.no/en/data-protectionservices/. Accessed 13 Oct 2021

Dawes, J. (2008). Do data characteristics change according to the number of scale points used? An experiment using 5-point, 7-point and 10-point scales. International Journal of Market Research, 50(1), 61-104. https://doi.org/10.1177/147078530805000106

Derby, E., Larsen, D., \& Schwaber, K. (2006). Agile retrospectives: Making good teams great. The Pragmatic Programmers.

Durney, C. P., \& Donnelly, R. G. (2015). Managing the effects of rapid technological change on complex information technology projects. Journal of the Knowledge Economy, 6(4), 641-664. https://doi.org/ 10.1007/s13132-012-0099-2

European Commission. https://ec.europa.eu/programmes/horizon2020/en/home. Accessed 13 Oct 2021

Fleming, L., Mingo, S., \& Chen, D. (2007). Collaborative brokerage, generative creativity, and creative success. Administrative Science Quarterly, 52(3), 443-475. https://doi.org/10.2189/asqu.52.3.443

Fornell, C., \& Larcker, D. F. (1981). Evaluating structural equation models with unobservable variables and measurement error. Journal of Marketing Research, 18(1), 39. https://doi.org/10.2307/3151312

Foss, N. J., Laursen, K., \& Pedersen, T. (2011). Linking customer interaction and innovation: The mediating role of new organizational practices. Organization Science, 22(4), 980-999. https://doi.org/10. 1287/orsc. 1100.0584

Galan-Muros, V., \& Davey, T. (2019). The UBC ecosystem: Putting together a comprehensive framework for university-business cooperation. The Journal of Technology Transfer, 44(4), 1311-1346. https:// doi.org/10.1007/s10961-017-9562-3

Grunbacher, P., \& Rabiser, R. (2013). Success factors for empirical studies in industry-academia collaboration: A reflection. 2013 1st International Workshop on Conducting Empirical Studies in Industry (CESI), 27-32. https://doi.org/10.1109/CESI.2013.6618466

Hair, J. F., Black B., Babin B. J., \& Anderson R. E. (2010). Multivariate data analysis : a global perspective (7th ed.). Pearson.

Hansen, I.-E., Mork, O. J., \& Welo, T. (2019a). Managing knowledge in manufacturing industry — University innovation projects. In IFIP Advances in Information and Communication Technology (Vol. 567, pp. 603610). https://doi.org/10.1007/978-3-030-29996-5_69

Hansen, I.-E., Mork, O. J., \& Welo, T. (2017). Knowledge management of university-industry collaboration in the learning economy. 2017 2nd International Conference on Knowledge Engineering and Applications (ICKEA), 173-177. https://doi.org/10.1109/ICKEA.2017.8169924

Hansen, I.-E., Mork, O. J., \& Welo, T. (2018). Towards a framework for managing knowledge integration in university-industry collaboration projects. Proceedings of the European Conference on Knowledge Management, ECKM, 2, 994-1002

Hansen, I.-E., Mork, O. J., Welo, T., \& Giske, L. A. L. (2019b). University-industry collaboration projects: A case of norway. ICICKM 2019 16th International Conference on Intellectual Capital Knowledge Management \& Organisational Learning, 177-185 
Hansen, I. E., Mork, O. J., \& Welo, T. (2019c). Exploring framework for university-industry innovation projects: building collaborative knowledge platform. Proceedings of the 20th European Conference on Knowledge Management, 1, 471-479. https://doi.org/10.34190/KM.19.148

Highsmith J (2009) Agile project management : creating innovative products, 2nd ed. Pearson Education, Upper Saddle River, N.J

Innovation project for the industrial sector. In The Research Council of Norway. https://www.forskningsradet. no/en/call-for-proposals/2020/innovation-project-for-the-industrial-sector/. Accessed 13 Oct 2021

Jacob, M., Hellström, T., Adler, N., \& Norrgren, F. (2000). From sponsorship to partnership in academyindustry relations. $R \& D$ Management, 30(3), 255-262

Jonsson, L., Baraldi, E., Larsson, L.-E., Forsberg, P., \& Severinsson, K. (2015). Targeting academic engagement in open innovation: Tools, effects and challenges for university management. Journal of the Knowledge Economy, 6(3), 522-550. https://doi.org/10.1007/s13132-015-0254-7

Joshi, A., Kale, S., Chandel, S., \& Pal, D. (2015). Likert scale: Explored and explained. British Journal of Applied Science \& Technology, 7(4), 396-403. https://doi.org/10.9734/BJAST/2015/14975

Kazadi, K., Lievens, A., \& Mahr, D. (2016). Stakeholder co-creation during the innovation process: Identifying capabilities for knowledge creation among multiple stakeholders. Journal of Business Research, 69(2), 525-540. https://doi.org/10.1016/j.jbusres.2015.05.009

Krogh, G. von, Ichijo, K., \& Nonaka, I. (2000). Enabling knowledge creation. In Enabling knowledge creation: How to unlock the mystery of tacit knowledge and release the power of innovation. Oxford University Press. https://doi.org/10.1093/acprof:oso/9780195126167.001.0001

Laine, K., Leino, M., \& Pulkkinen, P. (2015). Open Innovation Between Higher Education and Industry. Journal of the Knowledge Economy, 6(3), 589-610. https://doi.org/10.1007/s13132-015-0259-2

Larsson, M., Wall, A., Norström, C., \& Crnkovic, I. (2006). Technology transfer: Why some succeed and some don't. Proceedings - International Conference on Software Engineering, 23-27. https://doi.org/10. $1145 / 1138046.1138055$

Lazonick, W. (2006). The innovative firm. Oxford University Press. https://doi.org/10.1093/oxfordhb/ 9780199286805.003 .0002

Lincoln, Y. S., \& Guba, E. E. (1986). Research, evaluation, and policy analysis: Heuristics for disciplined inquiry. Review of Policy Research, 5(3), 546-565. https://doi.org/10.1111/j.1541-1338.1986.tb00429.x

Lundvall, B.-^. (2012). National systems of innovation. In B.-A. Lundvall (Ed.), National systems of innovation (Vol. 1). Anthem Press. https://doi.org/10.7135/UPO9781843318903

Marchesi, M., Mannaro, K., Uras, S., \& Locci, M. (2007). Distributed scrum in research project management. In Agile processes in software engineering and extreme programming: LNCS (Vol. 4536, pp. 240-244). Springer Berlin Heidelberg. https://doi.org/10.1007/978-3-540-73101-6_45

Maughan, D., Balenson, D., Lindqvist, U., \& Tudor, Z. (2013). Crossing the "Valley of Death": Transitioning cybersecurity research into practice. IEEE Security \& Privacy, 11(2), 14-23. https://doi.org/10. 1109/MSP.2013.31

Milliken, F. J., Bartel, C. A., \& Kurtzberg, T. R. (2003). Diversity and creativity in work groups. In Group Creativity (pp. 32-62). Oxford University Press. https://doi.org/10.1093/acprof:oso/9780195147308. 003.0003

Nelson, B. (2008). Flexible product development: Building agility for changing markets by Preston G. Smith. Journal of Product Innovation Management, 25(3), 303-304. https://doi.org/10.1111/j.15405885.2008.00302.x

Nonaka, I., \& Takeuchi, H. (1995). The knowledge-creating company: How Japanese companies create the dynamics of innovation. Oxford University Press.

Nonaka, I., Toyama, R., \& Konno, N. (2000). SECI, Ba and leadership: A unified model of dynamic knowledge creation. Long Range Planning, 33(1), 5-34. https://doi.org/10.1016/S0024-6301(99) 00115-6

Nonaka, I., von Krogh, G., \& Voelpel, S. (2006). Organizational knowledge creation theory: Evolutionary paths and future advances. Organization Studies, 27(8), 1179-1208. https://doi.org/10.1177/ 0170840606066312

Pallant, J. (2020). SPSS survival manual: A step by step guide to data analysis using IBM SPSS (7th ed.). Open University Press.

Perkmann, M., Fini, R., Ross, J.-M., Salter, A., Silvestri, C., \& Tartari, V. (2015). Accounting for universities' impact: Using augmented data to measure academic engagement and commercialization by academic scientists. Research Evaluation, 24(4), 380-391.

Perkmann, M., Salandra, R., Tartari, V., McKelvey, M., \& Hughes, A. (2021). Academic engagement: A review of the literature 2011-2019. Research Policy, 50(1), 104114 
Pertuzé, J. A., Calder, E. S., Greitzer, E. M., \& Lucas, W. A. (2010). Best practices for industry-university collaboration. MIT Sloan Management Review, 51(4), 83-90

Principles behind the Agile Manifesto. In https://agilemanifesto.org/principles.html. Accessed 13 Oct 2021

Project Bank. In The Research Council of Norway. https://prosjektbanken.forskningsradet.no/en/\#/ Sprak=en. Accessed 13 Oct 2021

Reagans, R., \& McEvily, B. (2003). Network structure and knowledge transfer: The effects of cohesion and range. Administrative Science Quarterly, 48(2), 240. https://doi.org/10.2307/3556658

Rigby, D. K., Sutherland, J., \& Noble, A. (2018). Agile at scale. Harvard Business Review, 96(3), 88-96

Rigby, D. K., Sutherland, J., \& Takeuchi, H. (2016a). Embracing agile. In Harvard Business Review (Vol. 2016, Issue May, pp. 40-48). Harvard Business School Publishing. https://hbr.org/2016/05/embracingagile?autocomplete $=$ true

Rigby, D. K., Sutherland, J., \& Takeuchi, H. (2016b). The secret history of agile innovation. Harvard Business Review, 7. https://hbr.org/2016/04/the-secret-history-of-agile-innovation

Ringdal, K. (2018). Enhet og mangfold : samfunnsvitenskapelig forskning og kvantitativ metode (4th ed.). Fagbokforlaget.

Sandberg, A. B., \& Crnkovic, I. (2017). Meeting industry-academia research collaboration challenges with agile methodologies. 2017 IEEE/ACM 39th International Conference on Software Engineering: Software Engineering in Practice Track (ICSE-SEIP), 73-82. https://doi.org/10.1109/ICSESEIP.2017.20

Sandberg, A., Pareto, L., \& Arts, T. (2011). Agile collaborative research: Action principles for industryacademia collaboration. IEEE Software, 28(4), 74-83. https://doi.org/10.1109/MS.2011.49

Schulze, A., Brojerdi, G., \& von Krogh, G. (2014). Those who know, do. those who understand, teach. Disseminative Capability and Knowledge Transfer in the Automotive Industry. Journal of Product Innovation Management, 31(1), 79-97. https://doi.org/10.1111/jpim.12081

Takeuchi, H., \& Nonaka, I. (1986). The new new product development game. Harvard Business Review, 64(1), 137-146

West, J., Salter, A., Vanhaverbeke, W., \& Chesbrough, H. (2014). Open innovation: The next decade. Research Policy, 43(5), 805-811. https://doi.org/10.1016/j.respol.2014.03.001

Wohlin, C., Aurum, A., Angelis, L., Phillips, L., Dittrich, Y., Gorschek, T., Grahn, H., Henningsson, K., Kagstrom, S., Low, G., Rovegard, P., Tomaszewski, P., van Toorn, C., \& Winter, J. (2012). The success factors powering industry-academia collaboration. IEEE Software, 29(2), 67-73. https://doi. org/10.1109/MS.2011.92

Yannou, B. (2013). Which research in design creativity and innovation? Let us not forget the reality of companies. International Journal of Design Creativity and Innovation, 1(2), 72-92. https://doi.org/ 10.1080/21650349.2013.754647

Zahra, S. A., \& George, G. (2002). Absorptive capacity: A review, Reconceptualization, and Extension. The Academy of Management Review, 27(2), 185. https://doi.org/10.2307/4134351

Zhang, Z., \& Sharifi, H. (2007). Towards theory building in agile manufacturing strategy -A taxonomical approach. IEEE Transactions on Engineering Management, 54(2), 351-370. https://doi.org/10. 1109/TEM.2007.893989

Publisher's Note Springer Nature remains neutral with regard to jurisdictional claims in published maps and institutional affiliations.

\section{Authors and Affiliations}

\section{Irina-Emily Hansen ${ }^{1} \cdot$ Ola Jon Mork ${ }^{1} \cdot$ Torgeir Welo $^{2} \cdot$ Geir Ringen $^{2}$}

1 Department of Ocean Operations and Civil Engineering, Norwegian University of Science and Technology, Aalesund, Norway

2 Department of Mechanical and Industrial Engineering, Norwegian University of Science and Technology, Trondheim, Norway 